\title{
Impact of direct substitution of arm span length for current standing height in elderly COPD
}

\author{
This article was published in the following Dove Press journal: \\ International Journal of COPD \\ 22 June 2015 \\ Number of times this article has been viewed
}

\section{Chaicharn Pothirat \\ Warawut Chaiwong \\ Nittaya Phetsuk}

Division of Pulmonary, Critical Care and Allergy, Department of Internal Medicine, Faculty of Medicine, Chiang Mai University, Chiang Mai, Thailand
Correspondence: Chaicharn Pothirat Division of Pulmonary, Critical Care and Allergy, Department of Internal Medicine, Faculty of Medicine, Chiang Mai University, I I0 Inthavaroros Road Sriphum, Maung Chiang Mai District, Chiang Mai 50200, Thailand

Tel +6653946228

Fax +6653895 II 7

Email cpothira@med.cmu.ac.th; chaicharn.p@cmu.ac.th
Background: Arm span length is related to standing height and has been studied as a substitute for current standing height for predicting lung function parameters. However, it has never been studied in elderly COPD patients.

Purpose: To evaluate the accuracy of substituting arm span length for current standing height in the evaluation of pulmonary function parameters and severity classification in elderly Thai COPD patients.

Materials and methods: Current standing height and arm span length were measured in COPD patients aged $>60$ years. Postbronchodilator spirometric parameters, forced vital capacity (FVC), forced expiratory volume in first second $\left(\mathrm{FEV}_{1}\right)$, and ratio of $\mathrm{FEV}_{1} / \mathrm{FVC}\left(\mathrm{FEV}_{1} \%\right)$, were used to classify disease severity according to global initiative for chronic obstructive lung disease criteria. Predicted values for each parameter were also calculated separately utilizing current standing height or arm span length measurements. Student's $t$-tests and chi-squared tests were used to compare differences between the groups. Statistical significance was set at $P<0.05$.

Results: A total of 106 COPD patients with a mean age of $72.1 \pm 7.8$ years, mean body mass index of $20.6 \pm 3.8 \mathrm{~kg} / \mathrm{m}^{2}$, and mean standing height of $156.4 \pm 8.3 \mathrm{~cm}$ were enrolled. The mean arm span length exceeded mean standing height by $7.7 \pm 4.6 \mathrm{~cm}(164.0 \pm 9.0$ vs $156.4 \pm 8.3 \mathrm{~cm}$, $P<0.001$ ), at a ratio of $1.05 \pm 0.03$. Percentages of both predicted FVC and $\mathrm{FEV}_{1}$ values based on arm span length were significantly lower than those using current standing height $(76.6 \pm 25.4$ vs $61.6 \pm 16.8, P<0.001$ and $50.8 \pm 25.4$ vs $41.1 \pm 15.3, P<0.001)$. Disease severity increased in $39.6 \%(42 / 106)$ of subjects using arm span length over current standing height for predicted lung function.

Conclusion: Direct substitution of arm span length for current standing height in elderly Thai COPD patients should not be recommended in cases where arm span length exceeds standing height by more than $4 \mathrm{~cm}$.

Keywords: chronic obstructive pulmonary disease, arm span, standing height, spirometry, severity

\section{Introduction}

Pulmonary function tests use standardized reference values based on ethnic and anthropometric characteristics, including age, sex, and height. ${ }^{1}$ It has become increasingly necessary to measure pulmonary function in patients who are unable to stand, as their current standing height cannot be accurately measured. ${ }^{2,3}$ The American Thoracic Society (ATS) and the European Respiratory Society (ERS) jointly recommend other options, including stated height or estimating from arm span when height cannot be measured. ${ }^{4}$

Substitution of standing height measurements can be estimated from arm span measurements using the appropriate regression equations and might be an alternative method to use for subjects in whom current standing height cannot be measured 
(eg, subjects with skeletal deformities or standing inability).,5 Substitution of arm span for standing height is important for assessment of predicted value of lung volume in elderly people with osteoporosis. ${ }^{7}$ One study suggested that standing height estimated using arm span could be directly substituted for actual height in adults for whom height could not be measured reliably. ${ }^{8}$ Other studies also suggested that arm span could be used for predicting lung function instead of height for elderly women ${ }^{9,10}$ and that $\mathrm{FEV}_{1}$ values using height and arm span were not statistically different in elderly individuals. $^{11,12}$

However, estimating height from arm span is controversial because the relationship between height and arm span varies with age and ethnicity. ${ }^{13-15}$ Although estimated height from arm span is highly correlated with standing height in general populations, there is very poor agreement with standing height in acutely ill elderly populations. ${ }^{16}$ A longitudinal study showed that actual standing height is lost from age 30 to 80 years, ${ }^{17}$ but arm span is still closely correlated to maximal standing height. ${ }^{18}$ Elderly COPD patients may lose their standing height more rapidly than normal aging populations due to direct effects of the disease like osteoporosis, irrespective of corticosteroid use, age, and sex. ${ }^{19-21}$ Therefore, substituting arm span measurement for actual height in estimating pulmonary function parameters should be investigated in COPD patients with advanced age. This study aimed to evaluate the use of arm span length as an alternative measure for the estimation of height and in the prediction of spirometry in elderly Thai COPD patients.

\section{Materials and methods Participants and study design}

We conducted a cross-sectional study enrolling Thai COPD patients who were more than 60 years of age and who were managed by pulmonologists at the chest clinic of Chiang Mai University Hospital, Chiang Mai, Thailand, between October 1, 2012 and September 30, 2013. Patients who were unable to stand, or had structural or neuromuscular defects, as well as subjects with chest or upper limb deformities were excluded. Accurate measurements of both standing height and arm span length in the same subjects were performed after the enrollment. Standing height was measured on barefooted subjects using a wall-mounted stadiometer (Zepper ZT160, China) while the subject was standing as tall as possible with buttocks, back, and head against the wall and looking straight ahead. Arm span was measured from tip-to-tip of middle fingers with hands maximally outstretched while standing against a wall, using a flexible calibrated steel tape measure
(Butterfly brand tape measure, China). Both measurements were taken to the nearest centimeter, and the mean values recorded. Arm span: standing height ratios were calculated separately for all subjects. All subjects underwent spirometric evaluation using a spirometer (Vmax series 22, Sensor Medics, Bilthoven, Holland). Postbronchodilator (400 $\mu \mathrm{g}$ of salbutamol), forced vital capacity (FVC), forced expiratory volume in first second $\left(\mathrm{FEV}_{1}\right)$, and ratio of $\mathrm{FEV}_{1} / \mathrm{FVC}$ were measured for all subjects using ATS/ERS standard guidelines. ${ }^{1}$ Values were calculated using National Health and Nutrition Examination Survey (NHANES) III reference equations. ${ }^{22}$ However, for Asians, a correction factor of 0.88 was applied to predicted $\mathrm{FVC}$ and $\mathrm{FEV}_{1} \cdot{ }^{23} \mathrm{COPD}$ was classified according to global initiative for chronic obstructive lung disease (GOLD) severity classification ${ }^{24}$ using both current standing height and arm span length measurements for each subject. We considered results clinically significant if the percentage of predicted $\mathrm{FEV}_{1}$ based on arm span differed by $5 \%$ or more from standing height calculations. ${ }^{20}$ The study protocol was approved by the Institutional Ethics Committee of the Faculty of Medicine, Chiang Mai University.

\section{Sample size calculation}

A standard deviation (SD) of $22 \mathrm{~cm}$ between arm span length and standing height in patients was previously estimated as significant. ${ }^{2}$ In the same study, the maximum acceptable difference between standing height and arm span length was set at $8 \mathrm{~cm}$. Our sample size calculation was based on the $95 \%$ confidence interval (CI), thus, keeping the type I error rate at 0.05 and probability (power) at 0.95 . A total of 100 patients was the minimum required sample size considered necessary to provide valid results.

\section{Statistical analysis}

Results for numerical values are expressed as mean $\pm \mathrm{SD}$, and those for categorical data are expressed as absolute frequencies and percentages. Categorical variables were analyzed using chi-square tests, whereas continuous variables were compared using Student's $t$-tests. Statistical significance was set at $P<0.05$. All analyses were carried out using the SPSS statistical package, version 16 for Windows (SPSS, Inc, Chicago, IL, USA).

\section{Results}

The baseline characteristics of all 106 enrolled COPD patients according to sex are shown in Table 1. Mean age of subjects was $72.1 \pm 7.8$ years, with a mean body mass index of $20.6 \pm 3.8 \mathrm{~kg} / \mathrm{m}^{2}$, and a mean standing height of $156.4 \pm 8.3 \mathrm{~cm}$. 
Table I Baseline characteristics according to sex and all patients

\begin{tabular}{|c|c|c|c|}
\hline Variables & Male & Female & COPD \\
\hline n (\%) & $69(65.1)$ & 37 (34.9) & $106(100)$ \\
\hline Age (years) & $72.5 \pm 7.2$ & $71.2 \pm 8.8$ & $72.1 \pm 7.8$ \\
\hline BMI $\left(\mathrm{kg} / \mathrm{m}^{2}\right)$ & $20.3 \pm 3.7$ & $21.1 \pm 4.0$ & $20.6 \pm 3.8$ \\
\hline Height (cm) & $159.9 \pm 6.9$ & $149.8 \pm 6.6$ & $156.4 \pm 8.3$ \\
\hline Arm span length $(\mathrm{cm})$ & $168.0 \pm 7.2$ & $156.7 \pm 7.3$ & $164.0 \pm 9.0$ \\
\hline Ratio of arm span/height & $1.05 \pm 0.03$ & $1.05 \pm 0.03$ & $1.05 \pm 0.03$ \\
\hline Arm span length minus height $(\mathrm{cm})$ & $8.1 \pm 4.8$ & $6.9 \pm 4.2$ & $7.7 \pm 4.6$ \\
\hline \multicolumn{4}{|c|}{ Pulmonary function test (based on current standing height) } \\
\hline $\mathrm{FVC}(\mathrm{L})$ & $2.07 \pm 0.48$ & $1.44 \pm 0.52$ & $1.85 \pm 0.57$ \\
\hline$\%$ predicted FVC & $84.8 \pm 25.9$ & $61.4 \pm 15.9$ & $76.6 \pm 25.4$ \\
\hline $\mathrm{FEV}_{1}(\mathrm{~L})$ & $1.06 \pm 0.35$ & $0.77 \pm 0.29$ & $0.96 \pm 0.36$ \\
\hline$\%$ predicted $\mathrm{FEV}$ & $55.8 \pm 23.5$ & $41.4 \pm 13.1$ & $50.8 \pm 25.4$ \\
\hline Ratio of $\mathrm{FEV}_{1} / \mathrm{FVC}(\%)$ & $50.5 \pm 11.5$ & $54.3 \pm 9.9$ & $51.8 \pm 11.0$ \\
\hline
\end{tabular}

Note: Data are presented in number $(\%)$, or mean \pm SD.

Abbreviations: BMI, body mass index; FVC, forced vital capacity; FEV , forced expiratory volume in first second; SD, standard deviation.

Mean standing height and arm span lengths were 156.4 \pm 8.3 and $164.0 \pm 8.3 \mathrm{~cm}$, respectively. Mean ratio of arm span length to current standing height was $1.05 \pm 0.03$. Arm span length exceeded current standing height by a mean length of $7.7 \pm 4.6 \mathrm{~cm}$. Mean percentage of predicted $\mathrm{FEV}_{1}$ was $50.8 \pm 25.4$ and mean ratio of $\mathrm{FEV}_{1}$ to $\mathrm{FVC}$ was $51.8 \pm 11.0$ based on current standing heights. Arm span measurements exceeded current standing height in 101 (95.3\%) patients, without significant difference between sexes (Table 2), and was categorized into four groups: <2.0, 2.0-3.9, 4.0-5.9, and $>5.9 \mathrm{~cm}$ comprising $6(5.7 \%), 10(9.4 \%), 19$ (17.9\%), and $71(67.0 \%)$ patients, respectively (Figure 1).

Table 3 shows spirometric data and GOLD classification based on current standing height and arm span length. Both percentage of predicted FVC and percentage of FEV, were significantly lower when based on arm span length compared to current standing height in both sexes. The variation between GOLD classification based on current standing height compared to arm span length was statistically significant $(P<0.001)$. Disease severity based on GOLD stage classification was 39.6\% (42/106) higher when standing height was used compared to arm span length, especially in males $(52.2 \%$ vs $16.2 \%$ in females, $P<0.001)$ (Table 4). When using arm span length, 41 cases (97.6\%) were one GOLD classification lower, and 1 case (2.4\%) was two GOLD classifications lower. In all, 69 subjects out of 90 had arm span lengths exceeding their respective standing heights by at least $4 \mathrm{~cm}$, resulting in decreased predicted $\mathrm{FEV}_{1}$ values $\geq 5 \%$, without significant differences between sexes (Table 5).

\section{Discussion}

Our study aimed to evaluate the use of arm span length as an alternative to standing height in the prediction of spirometry in elderly Thai COPD patients. The results revealed that the percentages of predicted FVC and $\mathrm{FEV}_{1}$ based on arm span length were significantly lower than current standing height in elderly Thai COPD patients. Both measures of percentages of predicted FVC and $\mathrm{FEV}_{1}$ were significantly underestimated when using arm span length compared to standing height (mean percent difference: $15.1 \pm 13.5$ and $9.7 \pm 9.9$, respectively). A clinical underestimation of at least $5 \%$ of the predicted $\mathrm{FEV}_{1}$ values was revealed in all subjects whose arm span length exceeded standing heights of at least $4 \mathrm{~cm}$. Underestimation of percentages of predicted FVC and $\mathrm{FEV}_{1}$ based on arm span length in this study resulted in significant reclassification ( $40 \%$ ) into a higher GOLD severity category. Treatment implications are different for patients classified into incorrect GOLD cateogies. ${ }^{24}$ Because the absolute mean difference between height and arm span in any

Table 2 Comparison of standing height and arm span length $(n=106)$

\begin{tabular}{|c|c|c|c|c|}
\hline Categories & Male $(n=69)$ & Female $(n=37)$ & COPD $(n=106)$ & $P$-value \\
\hline Arm span length exceeded standing height & $66(95.7)$ & $35(64.6)$ & $101(95.3)$ & 0.902 \\
\hline Arm span length equaled standing height & $\mathrm{I}(\mathrm{I} .4)$ & I (2.7) & $2(1.9)$ & \\
\hline Arm span length less than standing height & $2(2.9)$ & I (2.7) & $3(2.7)$ & \\
\hline
\end{tabular}

Notes: Data are presented in number (\%); P-value compared between sex groups using chi-square test. 


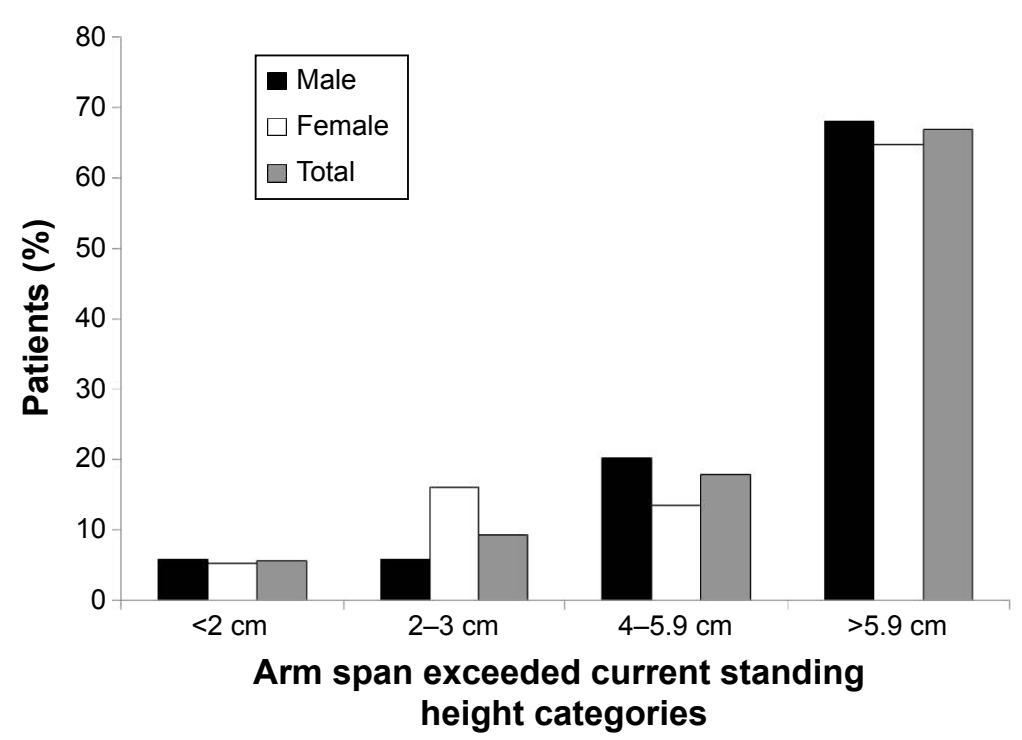

Figure I Percentage of patients whose arm span length exceeded standing height according to sex and all patients.

Note: $P=0.330$ compared between sex groups using chi-square test.

Table 3 Spirometric data and GOLD classification based on standing height and arm span length

\begin{tabular}{|c|c|c|c|c|c|c|}
\hline \multirow[t]{2}{*}{ Variables } & \multicolumn{2}{|l|}{ Male $(n=69)$} & \multicolumn{2}{|l|}{ Female $(n=37)$} & \multicolumn{2}{|l|}{ COPD $(n=106)$} \\
\hline & $\begin{array}{l}\text { Base on } \\
\text { standing height }\end{array}$ & $\begin{array}{l}\text { Base on arm } \\
\text { span length }\end{array}$ & $\begin{array}{l}\text { Base on } \\
\text { standing height }\end{array}$ & $\begin{array}{l}\text { Base on arm } \\
\text { span length }\end{array}$ & $\begin{array}{l}\text { Base on } \\
\text { standing height }\end{array}$ & $\begin{array}{l}\text { Base on arm } \\
\text { span length }\end{array}$ \\
\hline $\begin{array}{l}\text { Height used to predict } \\
\text { pulmonary function }\end{array}$ & $159.9 \pm 86.9$ & $168.0 \pm 7.2^{\mathrm{a}}$ & $149.8 \pm 6.6$ & $156 \pm 7.3^{\mathrm{a}}$ & $156.4 \pm 8.3$ & $164.0 \pm 9.0^{\mathrm{a}}$ \\
\hline \multicolumn{7}{|l|}{ Pulmonary function test } \\
\hline$\%$ predicted FVC & $84.8 \pm 25.9$ & $65.4 \pm 17.3^{\mathrm{a}}$ & $61.4 \pm 15.9$ & $54.4 \pm 13.1^{\mathrm{a}}$ & $76.6 \pm 25.4$ & $61.6 \pm 16.8^{\mathrm{a}}$ \\
\hline \% predicted $\mathrm{FEV}$ & $55.8 \pm 23.5$ & $43.2 \pm 16.6^{\mathrm{a}}$ & $41.4 \pm 13.1$ & $37.3 \pm 11.7^{\mathrm{a}}$ & $50.8 \pm 25.4$ & $41.1 \pm 15.3^{a}$ \\
\hline \multicolumn{7}{|l|}{ GOLD classification ${ }^{\mathrm{b}}$} \\
\hline 1 & $8(11.06)$ & $2(2.9)$ & I (2.7) & $0(0.0)$ & $9(8.5)$ & $2(1.9)$ \\
\hline$\|$ & $33(47.8)$ & $18(26.1)$ & $7(18.9)$ & $6(16.2)$ & $40(37.7)$ & $24(22.6)$ \\
\hline III & $21(30.4)$ & $32(46.4)$ & $22(59.5)$ & $21(56.8)$ & $43(40.6)$ & $53(50.0)$ \\
\hline IV & $7(10.1)$ & $17(24.6)$ & $7(18.9)$ & $10(27.0)$ & 14 (I3.2) & $27(25.5)$ \\
\hline
\end{tabular}

Notes: Data are presented in number (\%), mean $\pm \mathrm{SD}$; ${ }^{\mathrm{P}}<0.00 \mathrm{I}$ compared between data based on standing height and arm span length, ${ }^{b}$ the severity classification were significantly different based on arm span length compared to standing height $(P<0.05)$.

Abbreviations: FVC, forced vital capacity; FEV , forced expiratory volume in first second; GOLD, Global initiative for chronic Obstructive Lung Disease; SD, standard deviation.

Table 4 GOLD classification changes based on substituting arm span length for standing height

\begin{tabular}{|c|c|c|c|c|c|c|c|c|}
\hline \multicolumn{2}{|c|}{$\begin{array}{l}\text { Male GOLD } \\
\text { classification based on }\end{array}$} & \multirow{2}{*}{$\begin{array}{l}\text { GOLD } \\
\text { classification } \\
\text { change }\end{array}$} & \multicolumn{2}{|c|}{$\begin{array}{l}\text { Female GOLD } \\
\text { classification based on }\end{array}$} & \multirow{2}{*}{$\begin{array}{l}\text { GOLD } \\
\text { classification } \\
\text { change }\end{array}$} & \multicolumn{2}{|c|}{$\begin{array}{l}\text { Total GOLD } \\
\text { classification based on }\end{array}$} & \multirow{2}{*}{$\begin{array}{l}\text { GOLD } \\
\text { classification } \\
\text { change }\end{array}$} \\
\hline $\begin{array}{l}\text { Standing } \\
\text { height } \\
(n=69)\end{array}$ & $\begin{array}{l}\text { Arm span } \\
\text { length } \\
(n=69)\end{array}$ & & $\begin{array}{l}\text { Standing } \\
\text { height } \\
(n=37)\end{array}$ & $\begin{array}{l}\text { Arm span } \\
\text { length } \\
(n=37)\end{array}$ & & $\begin{array}{l}\text { Standing } \\
\text { height } \\
(n=106)\end{array}$ & $\begin{array}{l}\text { Arm span } \\
\text { length } \\
(n=106)\end{array}$ & \\
\hline \multirow[t]{3}{*}{18} & 12 & 6/8 (75.0) & 11 & 10 & I/I (I00.0) & 19 & 12 & $7 / 9$ (77.8) \\
\hline & II 5 & & & II I & & & 116 & \\
\hline & III I & & & - & & & III I & \\
\hline \multirow[t]{2}{*}{ II 33} & II 13 & $20 / 33(60.6)$ & II 7 & II 5 & $2 / 7(28.6)$ & II 40 & II 18 & $22 / 40(55.0)$ \\
\hline & III 20 & & & III 2 & & & III 22 & \\
\hline \multirow[t]{2}{*}{ III 2 I } & III II & $10 / 2 \mid(47.6)$ & III 22 & III 19 & $3 / 22(13.6)$ & III 43 & III 30 & I3/43 (30.2) \\
\hline & IV 10 & & & IV 3 & & & IV 13 & \\
\hline \multirow[t]{2}{*}{ IV 7} & IV 7 & - & IV 7 & IV 7 & - & IV 7 & IV 7 & - \\
\hline & & $36 / 69(52.2)$ & & & $6 / 37(16.2)^{\mathrm{a}}$ & & & $42 / 106$ (39.6) \\
\hline
\end{tabular}

Notes: Data are presented in number (\%); $P<0.00$ I compared between sex groups using chi-square test.

Abbreviation: GOLD, Global initiative for chronic Obstructive Lung Disease. 
Table 5 The proportion of COPD subjects within each arm span exceed height category where the difference in percent predicted FEV , exceed $5 \%$ point

\begin{tabular}{llll}
\hline $\begin{array}{l}\text { Arm span exceed } \\
\text { height category }(\mathbf{c m})\end{array}$ & \multicolumn{2}{l}{ Patients with \% predicted FEV , reduction exceed 5\% point } & P-value \\
\cline { 2 - 4 } & Male $(\mathbf{n}=\mathbf{6 9})$ & Female $(\mathbf{n}=\mathbf{3 7})$ & Total $(\mathbf{n}=\mathbf{1 0 6})$ \\
\hline$<2$ & - & - & - \\
$2-3.9$ & - & - & - \\
$4-5.9$ & $13 / 14(92.9)$ & $1 / 5(20.0)$ & $14(73.7)$ \\
$>5.9$ & $43 / 47(91.5)$ & $12 / 24(50.0)$ & $55(77.5)$ \\
\hline
\end{tabular}

Notes: Data are presented in number (\%), P-value compared between sex groups using chi-square test.

Abbreviations: $\mathrm{FEV}_{1}$, forced expiratory volume in first second; GOLD, Global initiative for chronic Obstructive Lung Disease.

individual is usually small (mean: $3.4-4.7 \mathrm{~cm}$ ) in previous studies, arm span was proposed as a direct substitution for height in prediction equations. ${ }^{8-10}$ Since this phenomenon is more marked in our elderly COPD patients, with an absolute mean difference between height and arm span almost twice higher $(7.7 \mathrm{~cm})$, a direct substitution of arm span length to current standing height incurred a significant underestimation of lung function and led to an almost $40 \%$ increase in GOLD severity classification. This should be considered as an incorrect interpretation of pulmonary function tests, misclassification of GOLD severity, and erroneous change in treatment regimen in elderly Thai COPD patients.

Our study should, therefore, draw attention to the potential discordance of arm span and height measurements in spirometric assessments of elderly COPD patients. Such a discrepancy may be related to ethnicity or may be due to extraordinary loss of current standing height as a result of COPD-related osteoporosis rather than the normal physiologic aging process. ${ }^{9,10}$ A previous longitudinal study suggests that current measured height may underestimate the progression of COPD, and that the use of arm span to determine height will give a more accurate measure of COPD progression. ${ }^{25}$ We disagree with this suggestion because arm span length significantly differed from current standing height in our study. Current standing height is one of the standard variables for pulmonary function measurement; therefore, we may not be able to reliably replace standing height with arm span. The potential clinical significance of the discrepancy between arm span and standing height, including underestimation of disease severity, should be taken into consideration. Once a method is chosen to estimate height, parameters required for arm span length or current standing height should be considered. When surrogate measures of height for elderly COPD patients are used in a clinical setting, data collection should not be mixed with the methods of height estimation.

Further investigation is needed for patients with osteoporosis, as they were not investigated in our study. Our study was limited because no height estimation regression equation using arm span length is available for Thai populations and because the study was conducted with a limited sample size of elderly COPD patients.

We suggest that until a regression equation correlating arm span length to standing height for Thai patients is developed, arm span length cannot be substituted for standing height when evaluating elderly Thai COPD patients.

\section{Conclusion}

Direct substitution of arm span length for current standing height in elderly Thai COPD patients cannot be recommended in cases where arm span length exceeds standing height by more than $4 \mathrm{~cm}$.

\section{Acknowledgments}

The authors wish to thank the subjects who kindly took part in this study and acknowledge the staff members of the Division of Pulmonary, Critical Care and Allergy, Department of Internal Medicine, Faculty of Medicine, Chiang Mai University for their contribution to this study.

\section{Author contributions}

The first author, Chaicharn Pothirat, developed the study design and carried out acquisition and interpretation of data, statistical analysis, manuscript preparation, and critical revision of intellectual contents. The remaining authors contributed to acquisition and interpretation of data, revised the article for important intellectual content, and gave final approval of the version to be published.

\section{Disclosure}

The authors report no conflicts of interest in this work.

\section{References}

1. Miller MR, Hankinson J, Brusasco V, et al. Standardisation of spirometry. Eur Respir J. 2005;26(2):319-338.

2. Sancho-Chust JN, Chiner E, Camarasa A, Senent C. Differences in pulmonary function based on height prediction obtained by using alternative measures. Respiration. 2010;79(6):461-468. 
3. Garcia-Rio F, Pino JM, Dorgham A, Alonso A, Villamor J. Spirometric reference equations for European females and males aged 65-85 years. Eur Respir J. 2004;24(3):397-405.

4. Pellegrino R, Viegi G, Brusasco V, et al. Interpretative strategies for lung function tests. Eur Respir J. 2005;26(5):948-968.

5. Capderou A, Berkani M, Becquemin M-H, Zelter M. Reconsidering the arm span-height relationship in patients referred for spirometry. Eur Respir J. 2011;37(1):157-163.

6. Golshan M, Amra B, Hoghoghi MA. Is arm span an accurate measure of height to predict pulmonary function parameters? Monaldi Arch Chest Dis. 2003;59(3):189-192.

7. Teramoto S, Matsuse T, Ouchi Y. Substitution of arm span for standing height is important for the assessment of predicted value of lung volumes in elderly people with osteoporosis. Chest. 1999;116(6):1837-1838.

8. Aggarwal AN, Gupta D, Jindal SK. Interpreting spirometric data: impact of substitution of arm span for standing height in adults from North India. Chest. 1999;115(2):557-562.

9. Leech JA, Dulberg C, Kellie S, Pattee L, Gay J. Relationship of lung function to severity of osteoporosis in women. Am Rev Respir Dis. 1990; 141(1):68-71.

10. Allen SC. The relation between height, arm span and forced expiratory volume in elderly women. Age Ageing. 1989;18(2):113-116.

11. Kwok T, Whitelaw MN. The use of arm span in nutritional assessment of the elderly. J Am Geriatr Soc. 1991;39(5):492-496.

12. Chhabra SK. Using arm span to derive height: impact of three estimates of height on interpretation of spirometry. Ann Thorac Med. 2008; 3(3):94-99.

13. Parker JM, Dillard TA, Phillips YY. Arm span-height relationships in patients referred for spirometry. Am J Respir Crit Care Med. 1996; 154(2 Pt 1):533-536.

14. Hibbert ME, Lanigan A, Raven J, Phelan PD. Relation of arm span to height and the prediction of lung function. Thorax.1988;43(8):657-659.

15. Reeves SL, Varakamin C. Henry CJ. The relationship between arm-span measurement and height with special reference to gender and ethnicity. Eur J Clin Nutr. 1996;50(6):398-400.
16. Hickson M, Frost G. A comparison of three methods for estimating height in the acutely ill elderly population. J Hum Nutr Diet. 2003; 16(1):13-20.

17. Sorkin JD, Muller DC, Andres R. Longitudinal change in height of men and women: implications for interpretation of the body mass index: the Baltimore Longitudinal Study of Aging. Am J Epidemiol. 1999;150(9):969-977.

18. Harris JA, Jackson CM, Paterson DG, Scammon RE. The Measurement of Man. Minneapolis, MN: University of Minnesota Press; 1930.

19. Ferguson GT, Calverley PM, Anderson JA, et al. Prevalence and progression of osteoporosis in patients with COPD: results from the TOwards a Revolution in COPD Health study. Chest. 2009;136(6): 1456-1465.

20. Kjensli A, Ryg M, Falch JA, et al. Does body height reduction influence interpretation of lung function in COPD patients? Eur Respir J. 2010;36(3):540-548.

21. Graat-Verboom L, Wouters EF, Smeenk FW, van den Borne BE, Lunde R, Spruit MA. Current status of research on osteoporosis in COPD: a systematic review. Eur Respir J. 2009;34(1):209-218.

22. Hankinson JL, Odencrantz JR, Fedan KB. Spirometric reference values from asample of the general US population. Am J Respir Crit Care Med. 1999;159(1):179-187.

23. Hankinson JL, Kawut SM, Shahar E, Smith LJ, Stukovsky KH, Barr RG. Performance of American Thoracic Society-recommended spirometry reference values in a multiethnic sample of adults: the multi-ethnic study of atherosclerosis (MESA) lung study. Chest. 2010;137(1):138-145.

24. Rabe KF, Hurd S, Anzueto A, et al. Global strategy for the diagnosis, management, and prevention of chronic obstructive pulmonary disease: GOLD executive summary. Am J Respir Crit Care Med. 2007;176(6): $532-555$.

25. Ansari K, Keaney N, Price M, et al. Precision in diagnosing and classifying COPD: comparison of historical height with current height and arm span to predict $\mathrm{FEV}_{1}$. Open Respir Med J. 2012;6:54-58.
International Journal of COPD

\section{Publish your work in this journal}

The International Journal of COPD is an international, peer-reviewed journal of therapeutics and pharmacology focusing on concise rapid reporting of clinical studies and reviews in COPD. Special focus is given to the pathophysiological processes underlying the disease, intervention programs, patient focused education, and self management protocols.

\section{Dovepress}

This journal is indexed on PubMed Central, MedLine and CAS. The manuscript management system is completely online and includes a very quick and fair peer-review system, which is all easy to use. Visit $\mathrm{http}: / /$ www.dovepress.com/testimonials.php to read real quotes from published authors. 